\title{
Phylogeography of southern brown and golden bandicoots: implications for the taxonomy and distribution of endangered subspecies and species
}

Authors: Cooper, Steven J. B., Ottewell, Kym, MacDonald, Anna J., Adams, Mark, Byrne, Margaret, et. al.

Source: Australian Journal of Zoology, 66(5-6) : 379-393

Published By: CSIRO Publishing

URL: https://doi.org/10.1071/ZO19052

BioOne Complete (complete.BioOne.org) is a full-text database of 200 subscribed and open-access titles in the biological, ecological, and environmental sciences published by nonprofit societies, associations, museums, institutions, and presses.

Your use of this PDF, the BioOne Complete website, and all posted and associated content indicates your acceptance of BioOne's Terms of Use, available at www.bioone.org/terms-of-use.

Usage of BioOne Complete content is strictly limited to personal, educational, and non - commercial use. Commercial inquiries or rights and permissions requests should be directed to the individual publisher as copyright holder.

BioOne sees sustainable scholarly publishing as an inherently collaborative enterprise connecting authors, nonprofit publishers, academic institutions, research libraries, and research funders in the common goal of maximizing access to critical research. 
Australian Journal of Zoology, 2018, 66, 379-393

https://doi.org/10.1071/ZO19052

\title{
Phylogeography of southern brown and golden bandicoots: implications for the taxonomy and distribution of endangered subspecies and species
}

\author{
Steven J. B. Cooper (D)A,B,L, Kym Ottewell (D) , Anna J. MacDonald ${ }^{\mathrm{D}, \mathrm{E}, \mathrm{F}}$, Mark Adams A,B,F, \\ Margaret Byrne ${ }^{\text {, }}$, Susan M. Carthew ${ }^{\mathrm{G}}$, Mark D. B. Eldridge (DH, You Li', Lisa C. Pope', \\ Kathleen M. Saint ${ }^{\mathrm{B}}$ and Michael Westerman (DK \\ A Australian Centre for Evolutionary Biology and Biodiversity and School of Biological Sciences, \\ The University of Adelaide, Adelaide, SA 5005, Australia. \\ ${ }^{B}$ Evolutionary Biology Unit, South Australian Museum, North Terrace, Adelaide, SA 5000, Australia. \\ ${ }^{C}$ Biodiversity and Conservation Science, Department of Biodiversity, Conservation and Attractions, Kensington, \\ WA 6151, Australia. \\ DThe John Curtin School of Medical Research, The Australian National University, Acton, ACT 2601, Australia.

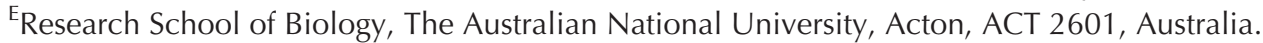 \\ FInstitute for Applied Ecology, University of Canberra, Canberra, ACT 2601, Australia. \\ ${ }^{G}$ Research Institute for Environment and Livelihoods, Charles Darwin University, Darwin, NT 0909, Australia. \\ ${ }^{\mathrm{H}}$ Australian Museum Research Institute, Australian Museum, Sydney, NSW 2010, Australia. \\ 'School of Life Sciences and Engineering and Biomedical Research Centre, Northwest Minzu University, \\ Lanzhou, Gansu 730030, China. \\ JInstitute for Social Science Research, Queensland University, Indooroopilly, Qld 4068, Australia. \\ KDepartment of Ecology, Environment and Evolution, La Trobe University, Melbourne, Vic. 3086, Australia. \\ ${ }^{\mathrm{L}}$ Corresponding author. Email: steve.cooper@samuseum.sa.gov.au
}

\begin{abstract}
Southern brown (Isoodon obesulus) and golden (Isoodon auratus) bandicoots are iconic Australian marsupials that have experienced dramatic declines since European settlement. Conservation management programs seek to protect the remaining populations; however, these programs are impeded by major taxonomic uncertainties. We investigated the history of population connectivity to inform subspecies and species boundaries through a broad-scale phylogeographic and population genetic analysis of Isoodon taxa. Our analyses reveal a major east-west phylogeographic split within I. obesulus/ I. auratus, supported by both mtDNA and nuclear gene analyses, which is not coincident with the current species or subspecies taxonomy. In the eastern lineage, all Tasmanian samples formed a distinct monophyletic haplotype group to the exclusion of all mainland samples, indicative of long-term isolation of this population from mainland Australia and providing support for retention of the subspecific status of the Tasmanian population (I. o. affinis). Analyses further suggest that I. o. obesulus is limited to south-eastern mainland Australia, representing a significant reduction in known range. However, the analyses provide no clear consensus on the taxonomic status of bandicoot populations within the western lineage, with further analyses required, ideally incorporating data from historical museum specimens to fill distributional gaps.
\end{abstract}

Additional keywords: Isoodon auratus, Isoodon obesulus.

Received 30 July 2019, accepted 27 November 2019, published online 8 January 2020

\section{Introduction}

It is often assumed that the taxonomy (species and subspecies classifications) and distribution of mammal species are now well established. However, even for well known species of conservation significance this assumption can be incorrect, and, in such cases, inaccuracies in taxonomic designations may have negative consequences for conservation management (Mace 2004; Gutiérrez and Helgen 2013; Zachos et al. 2013; Burgin et al. 2018). For example, poor taxonomy can fail to identify that an apparently widespread and low-risk species consists of multiple species or subspecies, some of which are rare or threatened (e.g. Adams et al. 2014; Ely et al. 2017). On the other 
hand, significant conservation resources may be applied to the protection of taxa that are conspecific with a common and widespread species (e.g. Laerm et al. 1982; Zachos et al. 2013).

The importance of resolving taxonomic uncertainties for conservation management of mammals is particularly relevant in Australia, where more than $10 \%$ of mammal species have become extinct since European settlement around 220 years ago, and a significant proportion $(\sim 21 \%)$ are now assessed to be threatened under International Union for Conservation of Nature Red List criteria (Woinarski et al. 2015). Grounddwelling mammals in the critical weight range of $35 \mathrm{~g}$ to $5.5 \mathrm{~kg}$ have been particularly impacted (Burbidge and McKenzie 1989; McKenzie et al. 2007), largely through predation by introduced feral cats (Felis catus) and red foxes (Vulpes vulpes) (Radford et al. 2018). Consequently, populations of some species now survive only on islands or in fenced exclosures on the mainland of Australia (e.g. Moseby et al. 2009; Woinarski et al. 2015; Legge et al. 2018). There is an ongoing need for conservation management of these remnant populations, with translocations currently being employed in several states of Australia to establish new populations and augment genetic diversity levels in existing populations (Weeks et al. 2011, 2017; Morris et al. 2015).

Two Australian species in the critical weight range that have seen dramatic declines in abundance and distribution are the southern brown bandicoot (Isoodon obesulus (Shaw, 1797)) and the golden bandicoot (Isoodon auratus (Ramsay, 1887)) (Paull 1993, 1995; Department of Environment and Conservation (NSW) 2006; Coates et al. 2008; Warburton and Travouillon 2016). These declines led to the National listing of the subspecies I. o. obesulus (Shaw, 1797) (southern and eastern mainland Australia) as Endangered, and the subspecies I. o. nauticus Thomas, 1922 (Franklin and St Francis islands of South Australia (SA)) as Vulnerable (Australian Environment Protection and Biodiversity Conservation (EPBC) Act Status 2012). The mainland population of I. auratus is also listed as Vulnerable (EPBC Act 2012), with subspecies restricted to small populations on several offshore islands. Population translocations for I. auratus and I. o. obesulus have recently been enacted or are planned (e.g. Ottewell et al. 2014; Pedler et al. 2018; Robinson et al.2018). Given these current and future conservation efforts, it is important that all key management decisions reflect a robust taxonomic framework, underpinned by the detailed population genetic analyses required to ensure that any deliberate mixing of populations does not result in outbreeding depression (loss of fitness due to crossing genetically divergent populations: Frankham et al. 2011). However, resolving the conservation status of these species and subspecies and developing strategies for their conservation management is hampered by significant and ongoing taxonomic uncertainty.

The taxonomy of species and subspecies within the genus Isoodon Desmarest, 1817 has been in a state of flux since the 19th century (Pope et al. 2001), with a range of taxonomic views continuing to be expressed in recent times, particularly for subspecies of $I$. obesulus (reviewed by Jackson and Groves 2015). Jackson and Groves (2015) listed four subspecies within I. obesulus: I. o. obesulus, I. o. fusciventer (J. Gray, 1841) from south-west Western Australia (WA), I. o. affinis (Waterhouse,
1846) from Tasmania and the insular I. o. nauticus (see Fig. 1 distribution map). More recently, I. o. fusciventer has been proposed as a distinct species, I. fusciventer, by Travouillon and Philips (2018), based mainly on phylogenetic position and teeth morphology. The related species I. peninsulae Thomas, 1922 from north Queensland was previously considered a subspecies of I. obesulus, but was also recently given specific rank following genetic studies by Westerman et al. (2012) and both morphological (skull characteristics) and genetic studies by Pope et al. (2001). However, to date, the World listing of mammal species (https://www.departments.bucknell.edu/ biology/resources/msw3/) recognises just two subspecies of I. obesulus (I. o. obesulus and I. o. nauticus), based originally on proposals by Groves (2005), and this taxonomic scheme has been utilised in several recent publications (Woinarski et al. 2014; Driessen and Rose 2015). Within the golden bandicoot, I. auratus (Ramsay, 1887), Jackson and Groves (2015) listed three subspecies: I. a. auratus (Ramsay, 1887) from the Kimberley region of WA, I. a. arnhemensis Lyne \& Mort, 1981 from the Northern Territory (NT), and I. a barrowensis (Thomas, 1901) from Barrow Island, WA, but the taxonomic status of $I$. $a$. arnhemensis has also been questioned (Westerman et al. 2012).

The recent taxonomic changes have been strongly influenced by the genetic studies of Westerman and Krajewski (2000), Pope et al. (2001), Zenger et al. (2005), Westerman et al. (2012) and, more recently, Travouillon and Philips (2018). With the exception of the latter two studies, which utilised nuclear gene markers, these studies were based on mitochondrial DNA (mtDNA) sequence data. The three earlier studies indicated that there was little genetic differentiation between I. obesulus and I. auratus and suggested that they should be synonymised as a single species (Pope et al. 2001; Zenger et al. 2005). In contrast, morphological data, indicate that I. obesulus and I. auratus can be distinguished by a range of characters, including size, skull and teeth characters and fur colour (Lyne and Mort 1981; Pope et al. 2001; Menkhorst and Knight 2011; Travouillon and Philips 2018). Zenger et al. (2005) suggested that there was little support for the genetic distinction of $I$. o. nauticus (suggesting its inclusion within I. o. obesulus), and also considered that $I$. $o$. affinis would most likely be placed within I. o. obesulus based on the allozyme data of Close et al. (1990). These taxonomic suggestions have major implications for the national conservation status of the endangered subspecies I. o. obesulus, because the Tasmanian subspecies, I. o. affinis, is not currently listed, and together these populations would be considered secure and of sufficient size to revoke the Endangered status of I. o. obesulus (e.g. see Woinarski et al. 2014). It is, therefore, important to consider the reliability of these existing genetic analyses for assessing species and subspecies boundaries of Isoodon bandicoots.

A major issue with the above conclusions on subspecies/ species status is that each study included very few samples (e.g. Close et al. 1990; Westerman et al. 2012; Travouillon and Philips 2018) and, generally, very little sequence data (e.g. mtDNA Control Region data ( $600 \mathrm{bp})$ only in the studies by Zenger et al. (2005) and Pope et al. (2001)). In particular, there have been limited mtDNA sequence data available for the Tasmanian subspecies, I. o. affinis, as no samples of this taxon were included in the studies by Pope et al. (2001) and Zenger 


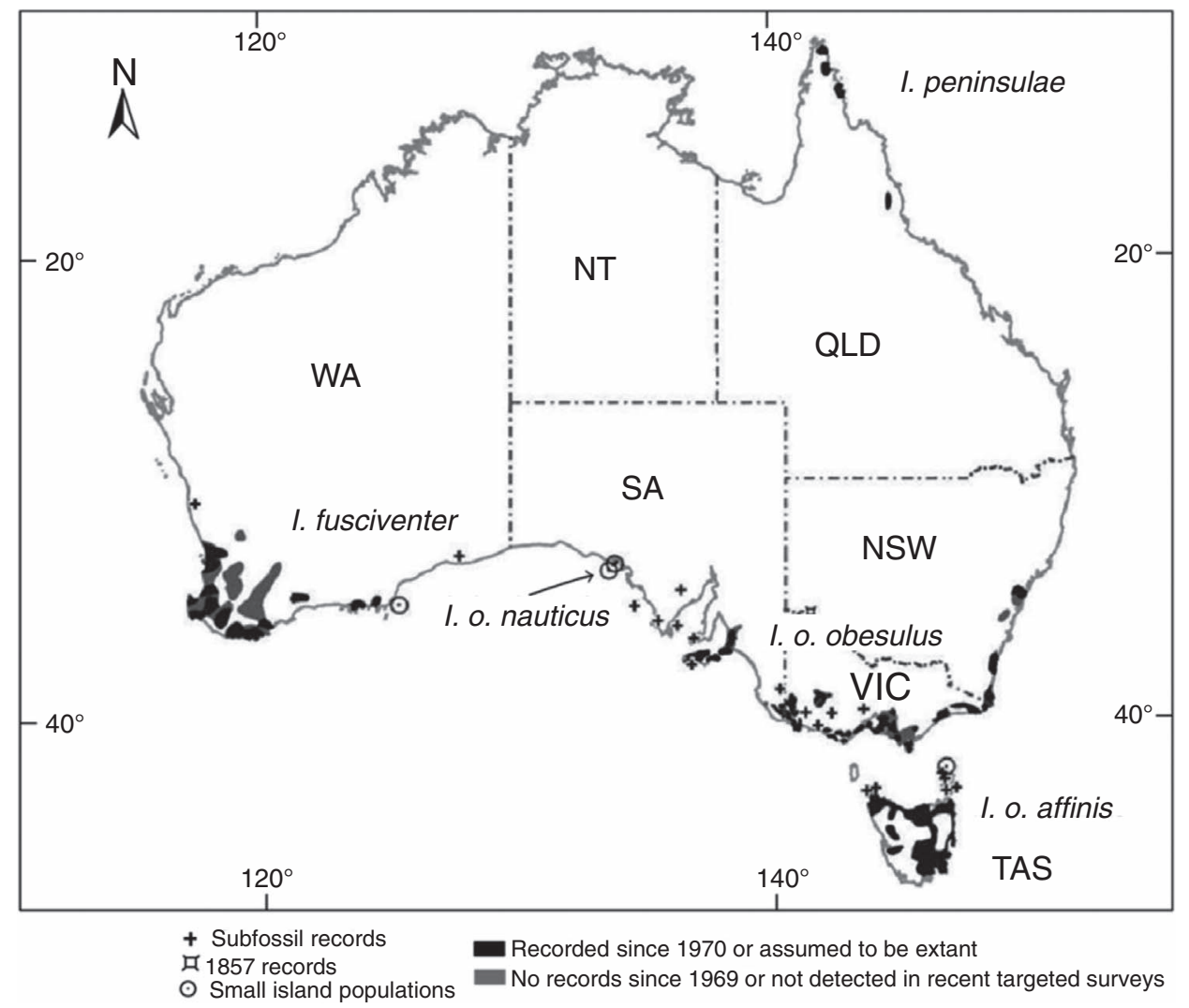

Fig. 1. Historical and extant distribution of subspecies of I. obesulus and closely related species I. fusciventer and I. peninsulae. The map was adapted from Paull et al. (2013).

et al. (2005), while the analysis by Westerman et al. (2012) included only one Tasmanian sample that grouped with a single I. o. obesulus individual from eastern Australia. Ideally, studies to inform taxonomic status should sample broadly from across the distribution of each species or subspecies and use multiple genetic loci (mtDNA and nuclear) to assess whether there is population differentiation associated with each discrete taxonomic unit. Long-term isolation of populations, either through allopatry (geographic) or reproductive isolation, leaves distinct patterns in gene trees over time, with a progression from polyphyly to paraphyly and then reciprocal monophyly of the discrete allopatric populations or reproductive units, although the timing of this progression is strongly influenced by population size (Avise 1994; Kingman 2000). Hence, resolution of taxonomic entities in southern brown and golden bandicoots still requires genetic studies that include appropriate sampling of each purported taxon, covering their full distribution in Australia, to assess their phylogeographic and population genetic structure and to determine whether they show long-term isolation from other taxa.

In comparison with studies at the taxon level, Li et al. (2014) recently carried out a genetic (microsatellite and mtDNA sequence) study of SA populations of I. o. obesulus, including populations from the Mt Lofty Ranges, Kangaroo Island and the south-east of SA. This study found that the Mt Lofty Ranges/ Kangaroo Island populations were genetically highly distinct from a population in the south-east of SA and western Victoria; the populations showed reciprocal monophyly and were considered to represent distinct Evolutionarily Significant Units (ESUs) based on the criteria of Moritz (1994). Furthermore, the Mt Lofty Ranges/Kangaroo Island populations were found to group with samples of I. fusciventer from WA, to the exclusion of all the east coast $I$. o. obesulus individuals, suggesting that the current recognised distribution of the latter subspecies may not represent an evolutionary unit (Li et al. 2014). Here, we have broadened the study of $\mathrm{Li}$ et al. (2014) to assess the phylogeographic structure of Isoodon taxa from across Australia and determine whether the subspecies and species are associated with distinct phylogeographic lineages (mtDNA sequence data) or fixed nuclear gene haplotypes. We also include evaluation of an earlier large-scale population genetic analysis based on allozyme electrophoresis for comparison with the phylogeographic analyses.

\section{Methods}

\section{Sample overview}

The analyses presented in this paper incorporate two largely independent genetic studies that have good coverage of samples from across the range of Isoodon in Australia: a recently gathered dataset based on DNA sequence analyses of mtDNA and nuclear gene markers, and an earlier one based on allozyme electrophoresis conducted between 1990 and 2013. Several of the same samples were analysed in both studies $(n=13$; see 
supplementary file 1; Table S1, Supplementary Material), but as allozyme electrophoresis requires fresh tissue samples, it was not feasible to use this technology on many of our recent samples (notably all the Tasmanian tissues), which included road kill tissues, ear tissue samples from ecological studies (Li et al. 2015, 2016), or old samples of DNA from past genetic studies (e.g. Pope et al. 2001). With respect to naming taxa within Isoodon, we have largely followed the taxonomic scheme of Jackson and Groves (2015), but have tentatively accepted I. fusciventer as a distinct species (Travouillon and Philips 2018). This scheme lists $I$. o. obesulus from east coast and southern Australia (including the Mt Lofty Ranges and Kangaroo Island in SA), I. fusciventer from south-west WA, I. o. affinis from Tasmania, I. o. nauticus from islands off the Eyre Peninsula in SA, I. peninsulae in northern Queensland, I. auratus barrowensis from Barrow Island in WA and I. auratus auratus from northern WA and the NT (see Fig. 2).

\section{DNA sequencing analyses}

DNA sequence analyses were based on a total of 158 samples from populations of I. obesulus, I. fusciventer, I. auratus, and I. peninsulae covering the distribution of the species and subspecies in Australia. These samples include 21 samples from Tasmania (including Flinders Island), 24 samples from southeastern mainland Australia (New South Wales (NSW), Victoria and south-east SA), 12 samples from the Franklin and St Francis
Islands (SA), 11 samples from the Mt Lofty Ranges (SA), 3 samples from Kangaroo Island (SA), 5 samples of I. peninsulae from north Queensland, 28 samples of I. auratus from WA and the NT, and 35 samples of I. fusciventer from WA (Fig. 2; Table S1, Supplementary Material). A further 17 samples from the related species Isoodon macrourus were also included in the genetic analyses. DNA was extracted from skin or liver tissue using the Gentra Puregene extraction kit and methods specified by the manufacturer (Gentra Systems Inc.), or by using the salting-out method described in MacDonald et al. (2011).

Two mitochondrial gene segments and three nuclear gene fragments were amplified: the noncoding control region $(C R)$, the NADH dehydrogenase subunit 2 (ND2); protein-coding portions of the breast and ovarian cancer susceptibility gene (BRCA1, exon 11), recombination activating gene-1 (RAG1, intronless) and vonWillebrand factor gene ( $V W F$, exon 28$)$. The primers used to amplify these genes and their annealing temperatures are listed in Table 1. PCR amplifications were carried out in $25-\mu \mathrm{L}$ volumes containing $0.1 \mathrm{U}$ AmpliTaq Gold ${ }^{\circledR}$ polymerase (Applied Biosystems), $1 \times$ Gold Buffer (Applied Biosystems), $0.20 \mathrm{~mm}$ dNTPs, $2.5 \mathrm{~mm} \mathrm{MgCl}_{2}, 0.5 \mu \mathrm{M}$ of each primer and $\sim 100 \mathrm{ng}$ genomic DNA. Thermocycling conditions were: initial activation at $94^{\circ} \mathrm{C}$ for $3 \mathrm{~min}$; 35 cycles of denaturation at $94^{\circ} \mathrm{C}$ for $30 \mathrm{~s}$, annealing at $48-55^{\circ} \mathrm{C}$ for $45 \mathrm{~s}$, and extension at $72^{\circ} \mathrm{C}$ for $60 \mathrm{~s}$; and a final extension at $72^{\circ} \mathrm{C}$ for $3 \mathrm{~min}$. PCR products were either (a) purified using Millipore

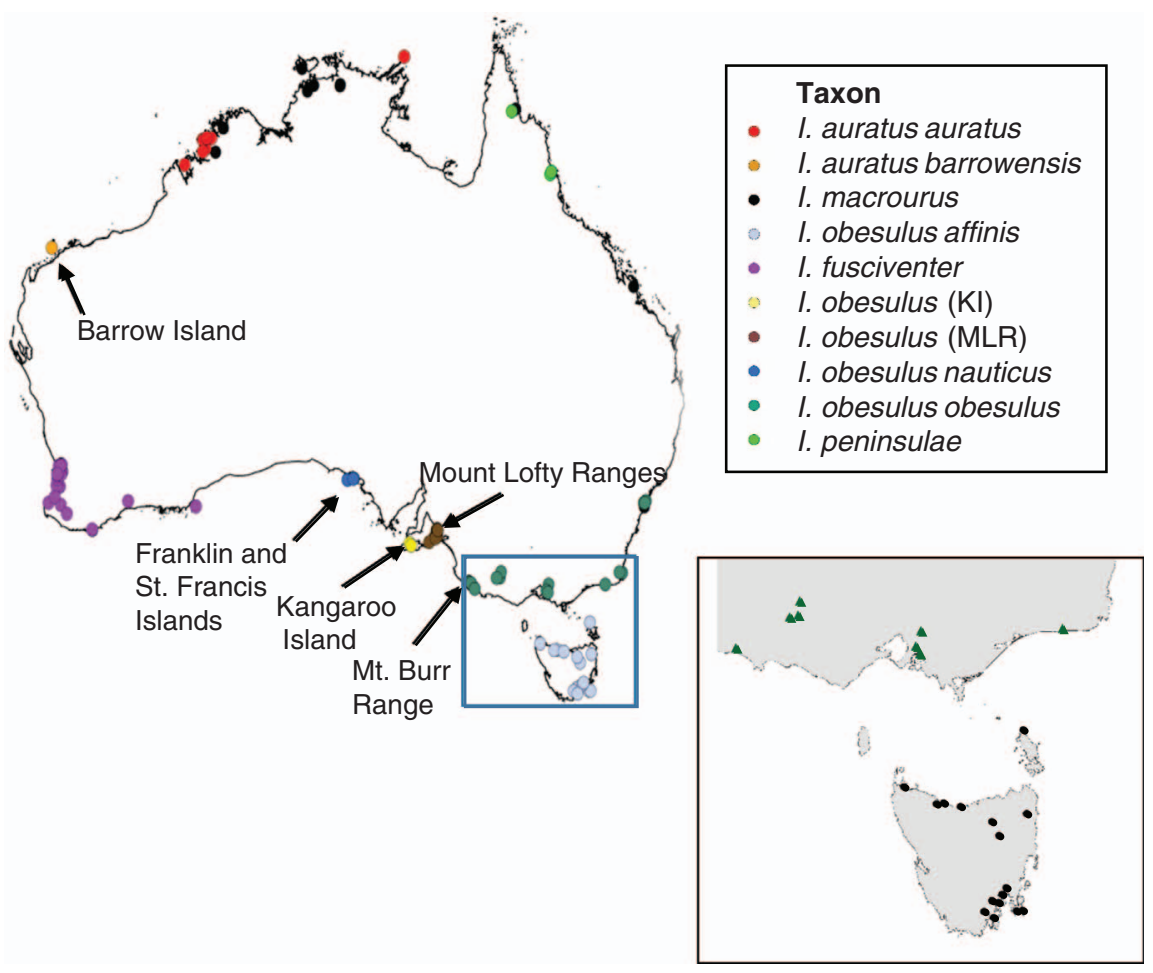

Fig. 2. Location of samples used for DNA sequence analyses collected from across Australia, including representatives of each of the major Isoodon taxa. The inset shows the locations of samples collected from Victoria (green triangles) and Tasmania (black circles). Further locality details are given in Table S1 (Supplementary Material). Symbols for population groups are: KI, Kangaroo Island; MLR, Mount Lofty Ranges. 
Table 1. Primers and annealing temperatures (Tm) used to amplify segments of $C R, N D 2, B R C A 1, R A G 1$ and $v W F$ from Isoodon taxa

\begin{tabular}{|c|c|c|c|c|}
\hline Gene & Primer name & Source & Sequence $\left(5^{\prime}-3^{\prime}\right)$ & $\mathrm{Tm}$ \\
\hline \multirow[t]{2}{*}{$C R$} & m989 (L15999M) & Fumagalli et al. (1997) & ACCATCAACACCCAAAGCTGA & $55^{\circ} \mathrm{C}$ \\
\hline & m990 (H16498M) & Fumagalli et al. (1997) & CCTGAAGTAGCAACCAGTAG & $55^{\circ} \mathrm{C}$ \\
\hline \multirow[t]{2}{*}{$N D 2$} & m635 (mmND2.1) & Osborne and Christidis (2001) & GCACCATTCCACTTYTGAGT & $48^{\circ} \mathrm{C}$ \\
\hline & m636 (mrND2c) & Osborne and Christidis (2001) & GATTTGCGTTCGAATGTAGCAAG & $48^{\circ} \mathrm{C}$ \\
\hline \multirow[t]{2}{*}{$B R C A 1$} & G1800 (F9) & Meredith et al. (2008) & AGTTCTGAAAGTGGATTCTTT & $50^{\circ} \mathrm{C}$ \\
\hline & G1801 (R-1MAC9-20) & Meredith et al. (2008) & CTGACCTRCAGCCTGAGGATTTCAT & $50^{\circ} \mathrm{C}$ \\
\hline \multirow[t]{2}{*}{$R A G 1$} & G2311 (F2204) & Amrine-Madsen et al. (2003) & GCTTCTGGCTCWGTCTACATYTGTAC & $50^{\circ} \mathrm{C}$ \\
\hline & G2312 (R2794) & Amrine-Madsen et al. (2003) & AAACGCTGTGARTTGAAACT & $50^{\circ} \mathrm{C}$ \\
\hline \multirow[t]{2}{*}{$v W F$} & G2313 (MF119) & Amrine-Madsen et al. (2003) & GACTTGGCYTTYCTSYTGGATGG & $55^{\circ} \mathrm{C}$ \\
\hline & G2314 (MR1140) & Amrine-Madsen et al. (2003) & TTGATCTCATCSGTRGCRGGATTGC & $55^{\circ} \mathrm{C}$ \\
\hline
\end{tabular}

MultiScreen PCR $_{384}$ Filter Plates (Millipore) and capillary Sanger-sequenced by the Australian Genome Research Facility or (b) purified using an ethanol/EDTA precipitation method and capillary Sanger-sequenced by the Australian Cancer Research Foundation Biomolecular Resource Facility (Australian National University, Canberra).

DNA sequences were edited and aligned using the Geneious alignment option within Geneious 6.1.4 (www.geneious.com). Pairwise distances (p-distances) among mitochondrial haplotypes were determined using Geneious. Geneious was also used to construct Neighbour Joining (NJ) trees, using the HKY-85 (Hasegawa et al. 1985) model of sequence evolution. Before concatenating the two mitochondrial genes $(C R+N D 2)$, we constructed separate phylogenetic trees to check their concordance. The robustness of nodes in the NJ trees was assessed by 1000 bootstrap replicates. A maximum likelihood (ML) analysis was also conducted using the program RAxML and the WEB-based RAxML 7.7.1 'black box' (http:// phylobench.vital-it.ch/raxml-bb/; Stamatakis et al. 2008; provided by the Vital-IT Unit of the Swiss Institute of Bioinformatics). A single model of evolution, the General Time Reversible (GTR) model (Rodríguez et al. 1990) with unequal variation at sites modelled using a Gamma $(G)$ distribution (Yang 1996), was applied to the concatenated sequence data. Robustness of branches on the tree was assessed using 100 bootstrap pseudoreplicates. Trees were rooted using I. macrourus as an outgroup; its sister lineage relationship to other Isoodon taxa was supported in the most recent multigene analysis of the genus by Travouillon and Philips (2018). Trees were visualised and prepared for publication using FigTree 1.4 .2 (http://tree.bio.ed.ac.uk/).

Average sequence divergence levels among haplotypes from subspecies and populations were determined using MEGA 6.0 (Tamura et al. 2013).

Because of the low sequence variation for the nuclear genes, we constructed haplotype networks to visualise the relationships among haplotypes. The phase of multiple ambiguities in the sequence data were resolved into distinct haplotypes using the program PHASE 2.1.1 (Stephens et al. 2001; Stephens and Scheet 2005). The distance-based (NJ) method and p-distances between sequences were used to derive a gene tree in Newick format, using Geneious, which was then used as input into the program Haploviewer (developed by G. Ewing: http://www. cibiv.at/ greg/haploviewer) to generate a haplotype network.

An assessment of how genetic variation was partitioned among hypothetical groups of populations was determined using Analyses of Molecular Variation (AMOVA), as implemented in the program Arlequin 3.5.2.2 (Excoffier and Lischer 2010), using default options based on frequency of, and p-distances among, haplotypes in populations. This approach was used to compare different hypotheses of species and subspecies boundaries for both mtDNA data and nuclear gene data. Tests of selective neutrality of the data were undertaken using Fu's FS (Fu 1997) and Tajima's D (Tajima 1989), as implemented in Arlequin.

\section{Allozyme analyses}

Allozyme electrophoresis was undertaken on cellulose acetate gels $\left(\right.$ Cellogel $\left.^{\odot}\right)$ using the methods employed by Southgate et al. (1996) for an earlier study focussing on I. auratus. Frozen tissues (liver, kidney or whole blood; blood chosen only when no other tissue type was available) were sourced from the SA Museum's Australian Biological Tissues Collection for 137 ingroup Isoodon and four outgroup ( $n=3$ Perameles nasuta; $n=1$ P. pallescens) specimens (Table S2, Supplementary Material). The following 47 presumptive loci displayed interpretable allozyme patterns in at least one tissue type: Acon1, Acon2, Acp, Acyc, Ada, Ak1, Ak2, Alb, Ca, Dia1, Dia2, Enol, Est, Fdp, Fum, G6pd, Gapd, Gda, Glo, Got1, Got2, Gpd, Gpi, Idh1, Idh2, Ldh1, Ldh2, Mdh1, Mdh2, Me1, Me2, Mpi, Ndpk, Np, PepA1, PepA2, PepB, PepD, Pgam, 6Pgd, Pgk, Pgm, Pk1, Pk2, Sod, Sordh, and $T p i$. Details of enzyme/locus nomenclature and abbreviations, enzyme commission numbers, electrophoretic conditions, and stain recipes are presented elsewhere (Richardson et al. 1986; Southgate et al. 1996).

The allozyme data were analysed using two complementary approaches. Initially, all ingroup individuals were subjected to stepwise Principal Coordinates Analysis ( $\mathrm{PCoA}$ ) following the rationale and methodology of Adams et al. (2014). This approach facilitates the identification of all diagnosable lineages/taxa from first principles, without assuming the taxonomic identity of individuals. Here we regard discrete PCoA groups as diagnosable lineages if they differed from one another by a minimum of two fixed differences (sensu Adams et al. 2014). 
Having confirmed that there were no discrepancies between an individual's a priori taxonomic identification and our PCoA findings, we then assessed the genetic affinities among all regional populations and diagnosable PCoA lineages within all described species or subspecies. This was achieved by constructing a NJ tree from a pairwise matrix of unbiased Nei's distances, rooted using the two outgroup taxa. All methodological details for producing this NJ tree are presented in Adams et al. (2013).

\section{Results}

\section{MtDNA sequence analyses}

MtDNA sequence data from CR ( 550 bp) and ND2 (629-698 bp) regions were obtained from 69 I. obesulus (including 21 I. o. affinis from Tasmania), 35 I. fusciventer samples, 27 I. auratus samples and 17 I. macrourus samples. Separate NJ analyses of $C R$ and ND2 revealed concordant phylogenetic trees and, therefore, the data were concatenated for further phylogenetic analyses using ML methods. There were no indels or premature stop codons evident in the ND2 data, suggesting that it was most likely mitochondrial DNA in origin rather than a nuclear copy of mtDNA. NJ and ML analyses of the concatenated data revealed similar phylogenetic trees, so we describe and present the ML tree only (Fig. 3; Fig. S1, Supplementary Material). Overall, there was evidence for considerable phylogenetic structure, with at least three major evolutionary lineages evident, one comprising samples of $I$. peninsulae from north Queensland, a second 'western and southern group' comprising I. fusciventer, I. auratus and I. obesulus (Mt Lofty Ranges, Kangaroo Island and Franklin and St Francis Islands) and a third comprising 'east coast' $I$. o. obesulus and Tasmanian I. o. affinis. The latter subspecies formed a distinct, well supported $(99 \%$ bootstrap value) monophyletic group that was in paraphyly with $I$. $O$. obesulus from the east coast of Australia (Fig. 3). Additional divergent mtDNA lineages were also evident within the "east coast' group (Fig. 3; Fig. S1, Supplementary Material): one occurring at Mt Burr in south-east SA, one from St Francis Island in SA, and one from Cranbourne in Victoria. Within the 'western and southern' group, considerable mtDNA diversity was evident,

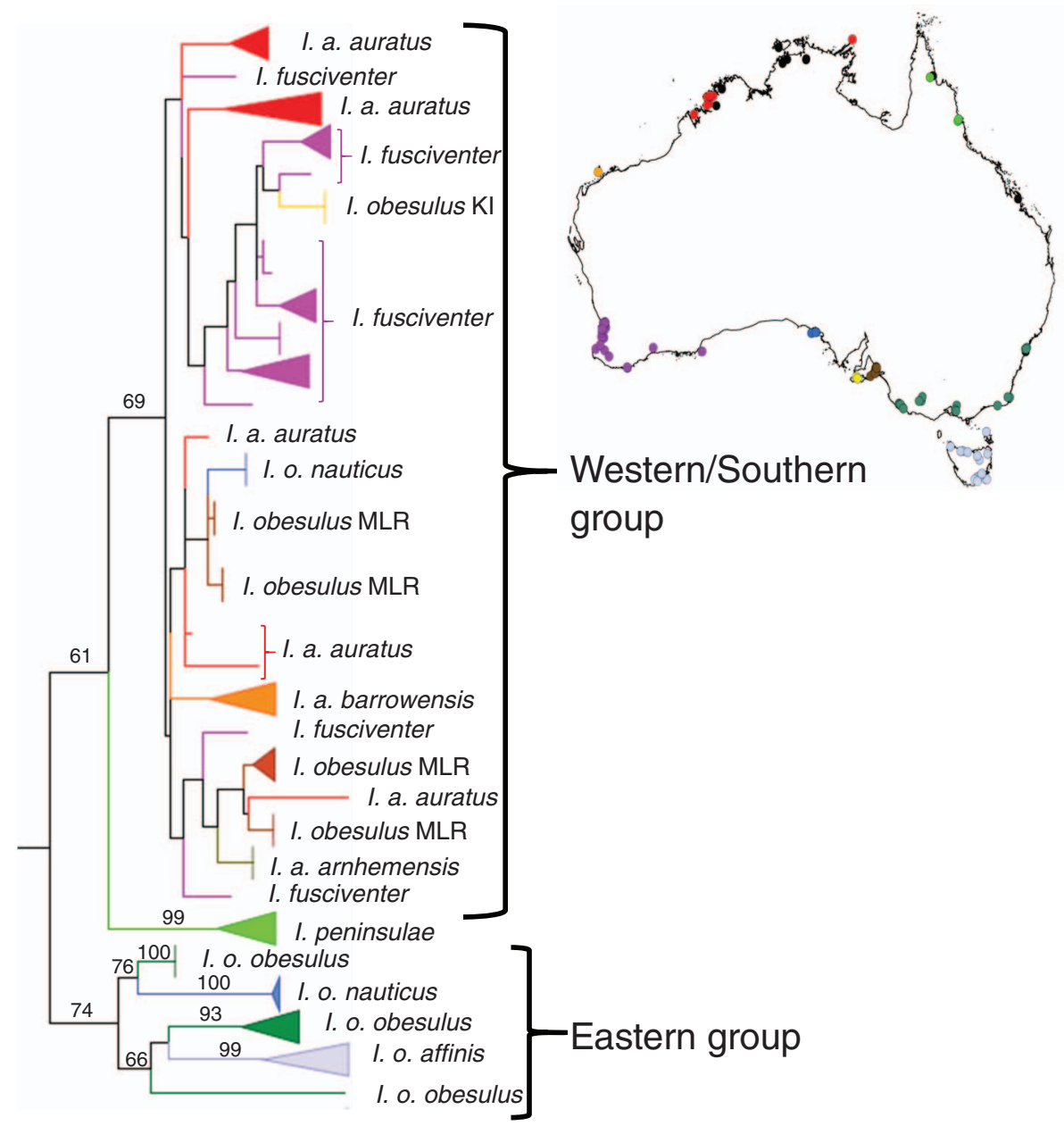

Fig. 3. Maximum likelihood phenogram derived using RAxML based on concatenated mtDNA sequence data from the NADH dehydrogenase subunit 2 gene (ND2) and Control Region $(C R)$ of Isoodon taxa. The tree was rooted using I. macrourus as an outgroup. Monophyletic groups of individuals from the same taxon have been collapsed to improve visualisation of the phenogram. The full trees are shown in Fig. S1 (Supplementary Material). Numbers above branches represent bootstrap values from 100 pseudoreplicates. 
with groups of divergent mtDNA haplotypes associated with each of the species, populations or subspecies, but no sharing of specific mtDNA haplotypes between entities. However, only I. auratus barrowensis formed a discrete monophyletic group, albeit with only three specimens sequenced, and the I. auratus auratus exemplars were polyphyletic with I. fusciventer and I. obesulus from the Mt Lofty Ranges (Fig. 3).

Estimates of average p-distances (ND2 and $C R$ data combined) among species/subspecies/populations ranged from 0.013 between the Kangaroo Island population of I. obesulus and I. fusciventer, to 0.038 between the Kangaroo Island population of I. obesulus and I. o. affinis from Tasmania (Table 2). The latter (I. o. affinis) showed a divergence level of 0.023 from I. o. obesulus from the south-east mainland of Australia. The Mt Lofty Ranges and Kangaroo Island populations showed the lowest divergences with I. fusciventer and I. auratus from WA, and diverged from east coast $I$. o. obesulus by p-distances of 0.035-0.036 (CR: 0.046-0.05; ND2: 0.025: Table S3, Supplementary Material).

\section{Nuclear sequence analyses}

Nuclear sequence data were derived from three genes, $v W F$, BRCA1 and RAG1, from 113, 81, and 116 Isoodon samples covering the range of each species (including I. macrourus) and subspecies in Australia (Fig. 2; Table S1, Supplementary Material). Low levels of divergence among sequences were observed for each gene, with a total of nine haplotypes identified for $R A G 1,11$ haplotypes identified for $B R C A 1$, and 21 haplotypes identified for $v W F$. Owing to the low levels of nucleotide variation, ancestral haplotypes may coexist with multiple descendent haplotypes and generation of bifurcating trees using standard phylogenetic analyses may not be appropriate. Hence a haplotype network approach was used to infer relationships among haplotypes and their associated populations (Fig. 4). We highlight below the distribution of private haplotypes among taxa and populations, but note that the privacy and frequency of haplotypes is likely to be influenced by sample size, which is not uniform across the distribution of taxa. Of the markers sequenced, $v W F$ was most informative, showing several private haplotypes that were fixed in different populations. For example, I. obesulus from the Mt Lofty Ranges, Kangaroo Island and the Franklin and St Francis Islands showed a fixed haplotype difference from all other populations/ subspecies; I. o. affinis (Tasmania) shared a haplotype with $I$. $o$. obesulus (east coast) and I. peninsulae. I. auratus had five private $v W F$ haplotypes and shared one common haplotype with I. peninsulae. I. fusciventer had two private haplotypes and a common one that was shared with I. a. barrowensis. I. macrourus had eight private haplotypes and shared no haplotypes with other Isoodon taxa. For BRCA1, although one common haplotype was shared among I. auratus, I. fusciventer, I. obesulus and I. macrourus, other haplotypes were private in different geographic regions. One $B R C A 1$ haplotype was found at high frequency in both $I$. o. obesulus (east coast) and $I$. $o$. affinis (Tasmania), one distinct haplotype was fixed within I. peninsulae and one was fixed within I. obesulus from the Mt Lofty Ranges, Kangaroo Island and the Franklin and St Francis Islands. In contrast, there was considerable haplotype sharing among species, subspecies and populations for two common $R A G 1$ haplotypes, with five private haplotypes detected in $I$. $a$. auratus and two private haplotypes detected in I. macrourus. However, one RAG1 haplotype was almost exclusively found in the Mt Lofty Ranges, Kangaroo Island, the Franklin and St Francis Islands, and I. fusciventer (WA).

\section{AMOVA}

For all mtDNA and nuclear gene markers, the grouping of samples from the Mt Lofty Ranges, Kangaroo Island and I. $o$. nauticus with I. o. obesulus and I. o. affinis (consistent with current classification of these populations) led to non-significant $(P>0.05)$ negative variances being estimated. In contrast, grouping samples from Mt Lofty Ranges, Kangaroo Island and I. o. nauticus together as a distinct group, or with I. fusciventer, gave positive and significant estimates of variance (Table 3). For two of the three nuclear gene markers ( $v W F$ and BRCA1), variation among groups was maximised for the tested species hypotheses when samples from Mt Lofty Ranges, Kangaroo Island and I. o. nauticus were grouped together as a group distinct from all other taxa (Table 3). For mtDNA data, variation among groups was maximised for the tested species hypotheses

Table 2. Estimates of average sequence divergence (p-distances) over sequence pairs (ND2 and $C R$ data combined) within (boxed on diagonal) and between (below diagonal) Isoodon species, subspecies and populations Symbols for subspecies/population groups are as follows: Im, I. macrourus; Ioa, I. obesulus affinis; Ioo, I. obesulus obesulus; Ion, I. obesulus nauticus; Iaa, I. auratus auratus; If, I. fusciventer; Iab, I. auratus barrowensis; Iok, I. obesulus Kangaroo Island SA; Iomlr, I. obesulus Mt. Lofty Ranges SA; Ip, I. peninsulae

\begin{tabular}{|c|c|c|c|c|c|c|c|c|c|c|}
\hline & Im & Ioa & Ioo & Ion & Iaa & If & $\mathrm{Iab}$ & Iok & Iomlr & Ip \\
\hline $\mathrm{Im}$ & 0.031 & & & & & & & & & \\
\hline Ioa & 0.094 & 0.008 & & & & & & & & \\
\hline Ioo & 0.092 & 0.023 & 0.009 & & & & & & & \\
\hline Ion & 0.091 & 0.033 & 0.031 & 0.017 & & & & & & \\
\hline Iaa & 0.086 & 0.036 & 0.035 & 0.021 & 0.013 & & & & & \\
\hline If & 0.089 & 0.036 & 0.035 & 0.023 & 0.016 & 0.009 & & & & \\
\hline $\mathrm{Iab}$ & 0.089 & 0.036 & 0.033 & 0.022 & 0.015 & 0.018 & 0.008 & & & \\
\hline Iok & 0.089 & 0.038 & 0.036 & 0.024 & 0.016 & 0.013 & 0.020 & \begin{tabular}{|l|}
0.000 \\
\end{tabular} & & \\
\hline Iomlr & 0.086 & 0.037 & 0.035 & 0.020 & 0.014 & 0.015 & 0.015 & 0.016 & \begin{tabular}{|l|}
0.009 \\
\end{tabular} & \\
\hline Ip & 0.087 & 0.037 & 0.035 & 0.030 & 0.027 & 0.025 & 0.026 & 0.028 & 0.026 & 0.003 \\
\hline
\end{tabular}




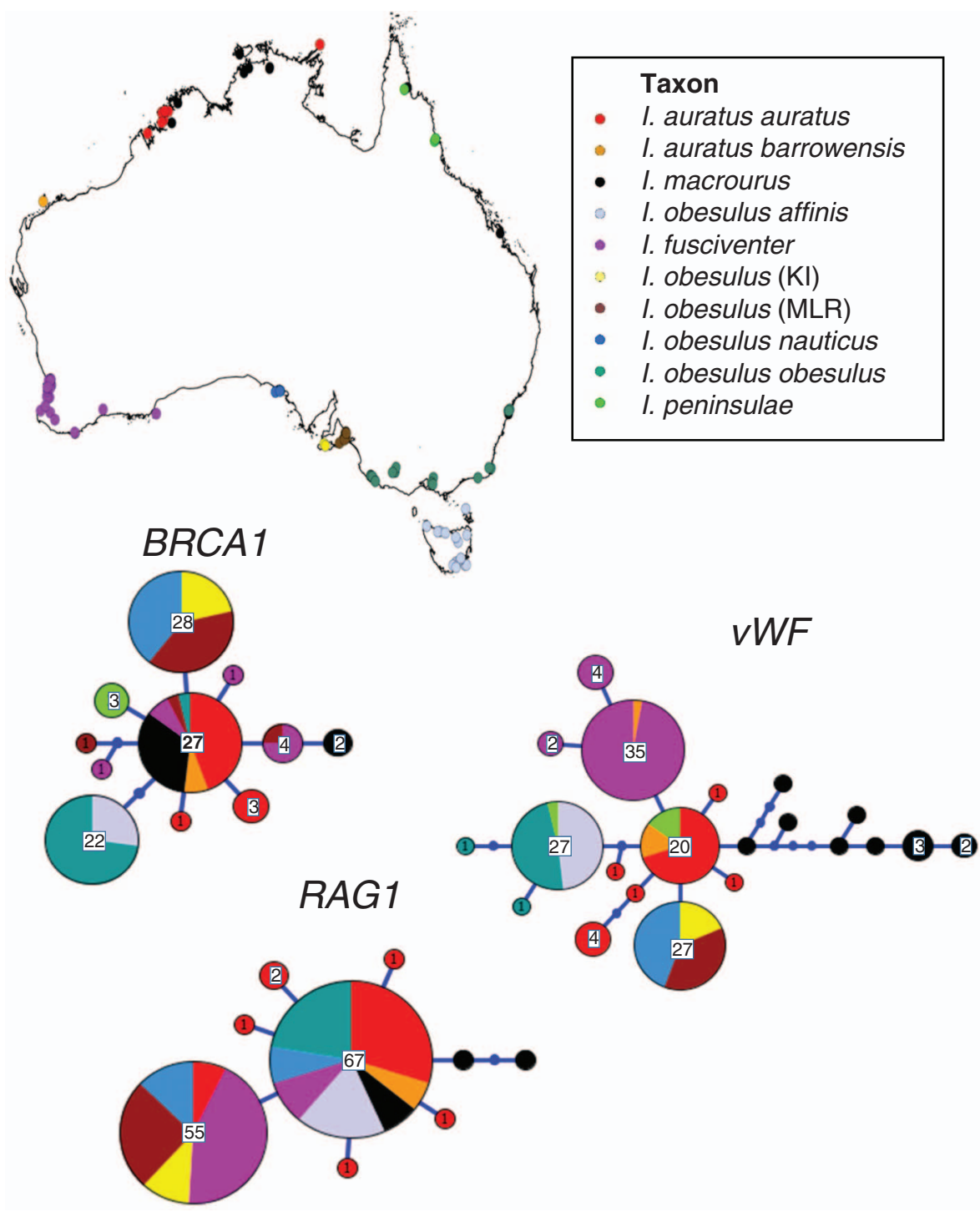

Fig. 4. Haplotype networks for three nuclear genes, $v W F, B R C A 1$ and $R A G 1$, based on Neighbour Joining trees and derived using the program Haploviewer (G. Ewing, http://www.cibiv.at/ greg/haploviewer). Colour codes for each of the populations are given in the key and their distribution is shown in the map. The frequency of the different haplotypes is shown within the circle. Small blue circles represent inferred haplotypes, not sequenced in the current study.

Table 3. Among-group genetic variation estimates from AMOVA analyses using Arlequin 3.5.2.2 for different species hypotheses *, significant at the $5 \%$ level; **, significant at the $1 \%$ level. Symbols for subspecies/population groups are as follows: Ioa, I. obesulus affinis; Ioo, I. obesulus obesulus; Ion, I. obesulus nauticus; Iaa, I. auratus auratus; If, I. fusciventer; Iab, I. auratus barrowensis; Iok, I. obesulus Kangaroo Island SA; Iomlr, I. obesulus

Mt. Lofty Ranges SA; Ip, I. peninsulae

\begin{tabular}{|c|c|c|c|c|c|}
\hline \multirow[t]{2}{*}{ Species hypothesis } & \multirow[t]{2}{*}{ Population groupings } & \multicolumn{4}{|c|}{ Genetic markers } \\
\hline & & mtDNA & vWf & BRCA1 & $\mathrm{RAG}^{\mathrm{A}}$ \\
\hline Current classification: 4 species & (Ioo,Ioa,Iomlr,Iok,Ion) (If) (Ip) (Iaa,Iab) & $-4.3 \%$ & $7.46 \%$ & $-12.01 \%$ & $-12.23 \%$ \\
\hline New taxon in SA (Iomlr,Iok,Ion): 5 species & (Ioo,Ioa) (Iomlr,Iok,Ion) (If) (Ip) (Iaa,Iab) & $24.07 \%$ & $85.25 \% * *$ & $83.03 \% * *$ & $53.10 \%$ \\
\hline I. fusciventer in SA: 4 species & (Ioo,Ioa) (Iomlr,Iok,Ion,If) (Ip) (Iaa,Iab) & $33.34 \% *$ & $39.75 \%$ & $70.50^{* *}$ & $61.19 \% *$ \\
\hline East-west and Ip: 3 species & (Ioo,Ioa) (Iomlr,Iok,Ion,If,Iaa,Iab) (Ip) & $47.08 \% * *$ & $53.06 \% *$ & $68.60 \% * *$ & $29.55 \%$ \\
\hline 7 taxa: subspecies and species & (Ioo) (Ioa) (Iomlr,Iok,Ion) (If) (Ip) (Iaa) (Iab) & $32.07 \%$ & $86.24 *$ & $81.16 \% *$ & $42.86 \%$ \\
\hline If and Ia synonymised: 4 species & (If,Iaa,Iab) (Iomlr,Iok,Ion) (Ip) (Ioo,Ioa) & $37.22 \% * *$ & $67.91 \% * *$ & $81.28 \% * *$ & $25.08 \%$ \\
\hline
\end{tabular}

\footnotetext{
${ }^{\mathrm{A}}$ No RAG1 data were obtained from I. peninsulae.
} 
with a 3-taxon grouping based on the east-west split of $I$. $o$. obesulus $+I$. o. affinis versus Mt Lofty Ranges, Kangaroo Island, I. o. nauticus, I. fusciventer and I. auratus, and with I. peninsulae representing the third group (Table 3). Fu's FS and Tajima D tests of selective neutrality for mtDNA data were all non-significant $(P>0.05$; results not shown).

\section{Allozyme analyses}

The final dataset comprised the allozyme profiles of 137 Isoodon (excluding I. o. affinis and I. peninsulae), three Perameles nasuta, one $P$. pallescens at 47 loci (data summarised in Table S2, Supplementary Material). Stepwise PCoA of all ingroup individuals (Fig. 5), coupled with complementary assessments of cluster diagnosability (Table S4, Supplementary Material), revealed the presence of five diagnosable groups, namely: NT/ WA I. macrourus; Queensland I. macrourus; I. auratus; I. o. obesulus; and a composite of I. fusciventer and all other western and southern subspecies/regional populations of I. obesulus. These diagnosable taxa are also evident in the NJ tree (Fig. 6), which shows a single group comprising individuals from I. fusciventer, I. o. nauticus and I. o. obesulus from the Mt Lofty Ranges and Kangaroo Island.

\section{Discussion}

Taxonomic assessment of entities in species complexes is often informed by multigene molecular analyses, which should include adequate sampling across the distribution of putative taxa. Here we have demonstrated this approach to evaluate taxonomic boundaries in the southern brown and golden bandicoots, a suite of related marsupial species of conservation significance that are the subject of major ongoing taxonomic uncertainty. The genetic analyses presented here considerably extend previous genetic analyses of the southern brown bandicoot (I. obesulus) and related species (I. fusciventer, I. peninsulae and I. auratus), particularly incorporating many additional samples from Tasmania and South Australia, which were poorly represented in past genetic studies (Pope et al. 2001; Zenger et al. 2005; Westerman et al. 2012). The results have important taxonomic and conservation management implications, particularly for eastern and southern Australian populations of I. obesulus. However, our data were still not sufficient to characterise the relationships among I. auratus, I. fusciventer and southern populations, previously recognised as I. o. obesulus. Further work, building on the analyses presented here, will be required to resolve these relationships.

\section{The taxonomic status of the Tasmanian and east coast populations of I. obesulus}

Our study included 21 samples of I. obesulus from across the range of the species in Tasmania (including Flinders Island). Phylogenetic analyses revealed that the Tasmanian exemplars were monophyletic for mtDNA haplotypes relative to $I$. $O$. obesulus from the south-east coast of mainland Australia. However, the latter did not show reciprocal monophyly of mtDNA haplotypes; a single haplotype from Mt Burr in southeast SA was more closely related to a haplotype from St Francis Island in SA, and a haplotype from Cranbourne, Victoria, also grouped outside the main $I$. o. obesulus east coast mtDNA clade. These findings indicate that $I$. o. obesulus (east coast) is a paraphyletic taxon based on analyses of mtDNA. The monophyly of the Tasmanian population and moderate level of sequence divergence $(\sim 2.3 \%)$ from $I$. o. obesulus provides evidence of long-term isolation of this population from the nearest mainland population. Given an observation that a 9.4\% mtDNA divergence level (ND2 and $C R$ combined for I. macrourus versus I. o. affinis: Table 2) here equates to an $\sim 2.4$

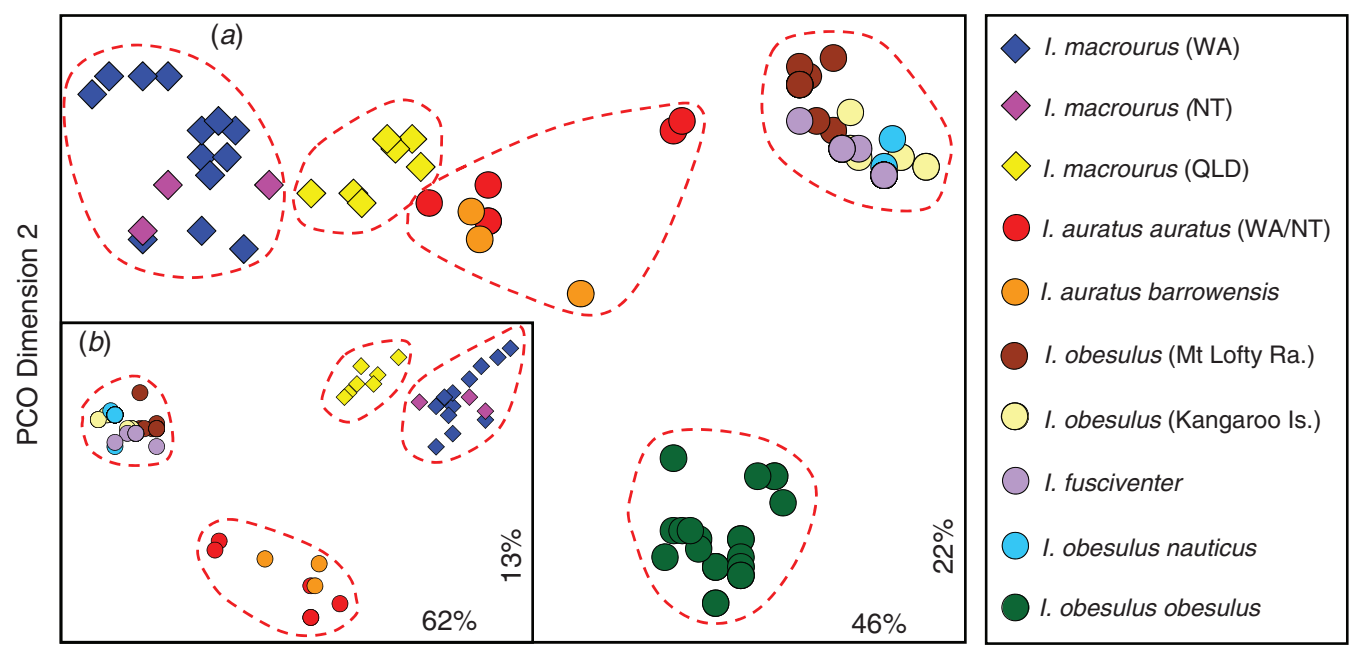

PCO Dimension 1

Fig. 5. Stepwise Principal Coordinates Analysis of the 137 Isoodon genotyped in the allozyme study. Relative PCoA scores have been plotted in the first two dimensions for $(a)$ the initial PCoA on all individuals, and $(b)$ a follow-up PCoA on the subset of individuals created by removing the most distinctive PCoA cluster (I. obesulus obesulus; $n=24)$. Individuals are labelled by taxon name or geographic lineage, according to the symbols provided (which match those used in other figures for Isoodon). Clusters enclosed within a dotted line are diagnosable from others by at least two fixed differences (Table S3, Supplementary Material). Note that individuals with identical multilocus genotypes will overlie each other. 


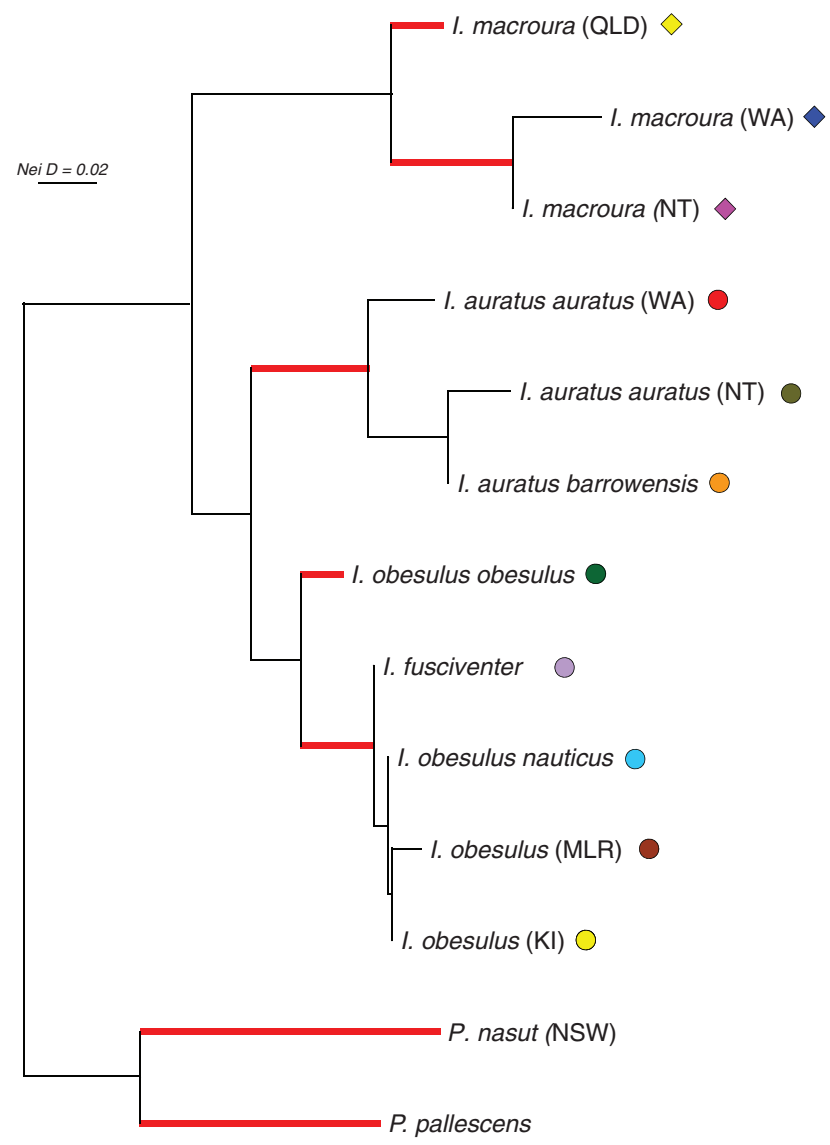

Fig. 6. Neighbour-joining tree for allozyme data, based on a matrix of pairwise unbiased Nei's distances among all regional populations and diagnosable PCoA lineages identified for species and subspecies of Isoodon. The tree was rooted using the two outgroup taxa of Perameles. Lineages that are diagnosable by a minimum of two fixed differences are identified by the thick (red) lines.

(1.5-2.7) million years divergence time estimate based on the study of Westerman et al. (2012), and assuming a strict molecular clock, a $2.3 \%$ level of divergence would equate to a coalescent time of $\sim 0.6(0.4-0.7)$ million years, representing a Pleistocene divergence period between the Tasmanian and south-east mainland populations. It should be noted that population divergence time is often substantially less than the coalescent time of individual genes and there can be considerable stochastic variation in coalescent time estimates at recent time scales (Ho et al. 2011). Hence, there is a need for additional nuclear gene analyses and alternative approaches to time estimation that model the isolation of populations (e.g. Isolation-Migration model: Hey 2010). However, given the above coalescent time estimates, it would seem unlikely that there has been any recent mtDNA gene flow between the Tasmanian population of I. obesulus and the mainland population of $I$. o. obesulus, despite having the opportunity to come into contact across the land bridge between Tasmania and the mainland during the last glacial maximum ( 15000 years ago). This finding is in contrast to observations from the eastern barred bandicoot (Perameles gunnii), which shows low ND2 sequence divergence $(<0.43 \%)$ among Tasmanian and mainland Australian populations and no evidence of monophyly of the Tasmanian population, suggesting that population connectivity occurred during the most recent land-bridge connection (MacDonald and Sarre 2017). The sugar glider (Petaurus breviceps) also shows low divergence of mtDNA between Tasmanian and mainland populations; however, in contrast, this is indicative of a recent invasion history (Campbell et al. 2018). Other marsupial taxa, for example, Potorous tridactylus, show phylogeographic structure and considerable genetic differentiation among Tasmanian and mainland populations, indicative of long-term isolation of their gene pools, via a barrier that most likely predated the recent flooding of Bass Strait (Frankham et al. 2016). This latter pattern is more in line with that found for I. obesulus.

For the nuclear DNA markers, $v W F, R A G 1$ and $B R C A 1$, there was no evidence for differentiation of east coast $I$. o. obesulus and the Tasmanian population of $I$. obesulus, with each population sharing identical haplotypes. However, the three genes are relatively slowly evolving and, for $v W F$ and $R A G l$ loci, the haplotypes observed in the Tasmanian population were also shared with $I$. peninsulae and I. macrourus respectively, suggesting that they represent ancestral haplotypes that became fixed in the Tasmanian population. Therefore, these two loci are essentially uninformative about whether there has been longterm genetic isolation of the Tasmanian population from $I$. $o$. obesulus (south-east coast). Similarly, the finding that these two populations shared an alternative $B R C A 1$ haplotype may reflect a historical connection, but should not be considered as evidence for recent population connectivity.

The monophyletic status and significant divergence of the Tasmanian population of $I$. obesulus from east coast $I$. $o$. obesulus, based on analyses of mtDNA, strongly supports their genetic distinction and long-term isolation. Past morphological analyses by Lyne and Mort (1981) also support the distinction of I. o. affinis from I. o. obesulus, though sample sizes for these comparisons were relatively low: Tasmanian individuals are larger with respect to their skull length, but skull width is notably smaller for Tasmanian males when compared with those found in Victoria and NSW, and so is ramus width for both males and females. Currently, a morphological re-evaluation is in progress for the genus Isoodon (Travouillon, pers. comm.). Together with a lack of information about population differentiation from the nuclear markers, we cannot support the recommendation of Zenger et al. (2005) to subsume I. o. affinis within I. obesulus, as adopted in the Action Plan for Australian Mammals (Woinarski et al. 2014). Indeed 'affinis' may represent a distinct species within Isoodon, but further analyses are required with more informative nuclear markers to help resolve the appropriate taxonomic designation for this population.

\section{The taxonomic status of South Australian populations} of I. obesulus

In a previous study, Li et al. (2014) proposed that the Mt Lofty Ranges and Kangaroo Island populations of I. obesulus represented a distinct ESU based on the criteria of Moritz (1994), compared with $I$. obesulus from south-eastern SA and western Victoria. Given the expectation that subspecies should represent discrete evolutionary lineages, or, at least, genetically 
differentiated populations (Avise and Bull 1990), the previous study suggested that the Mt Lofty Ranges and Kangaroo Island populations should be regarded as a separate taxon different from I. o. obesulus. The current study verified this conclusion and showed that animals from the Mt Lofty Ranges, Kangaroo Island and Franklin and St Francis islands of South Australia, currently recognised as I. o. obesulus, are more closely related to I. fusciventer and I. auratus from WA than to the east coast subspecies I. o. obesulus and Tasmanian I. o. affinis. On the basis of mtDNA sequence data, both the Mt Lofty Ranges and Kangaroo Island populations comprised distinct groups of haplotypes that are embedded within the 'western/southern group' that includes I. fusciventer and I. auratus. The high level of divergence in mtDNA $(>3.5 \%$ combined data; $>4.6 \%$ for $C R$ and $2.5 \%$ for ND2) from populations of $I$. o. obesulus from south-eastern SA and east coast Australia, suggests that there has been long-term isolation of these populations.

The distinction of the Mt Lofty Ranges and Kangaroo Island populations from animals currently recognised as I. o. obesulus was also supported by the nuclear gene analyses, where they showed fixed haplotype differences, when compared with $I$. $O$. obesulus and I. o. affinis, for $v W F, B R C A$ and $R A G 1$. Indeed, the nuclear data revealed a close association of the Mt Lofty Ranges/ Kangaroo Island populations with I. o. nauticus from the Franklin and St Francis Islands, with each of these populations sharing a distinct $v W F$ and $B R C A 1$ haplotype that was not found in any other Isoodon population in Australia. They also shared a RAG1 haplotype that was detected at high frequency in I. fusciventer. Similarly, the allozyme analyses also support a close association between the Mt Lofty Ranges/Kangaroo Island/ I. o. nauticus group and I. fusciventer, the taxa only showing several allelic differences and no fixed differences (Table S4, Supplementary Material). Overall, the mitochondrial and all nuclear data confirm the close association of the Mt Lofty Ranges, Kangaroo Island and Franklin and St Francis Island populations and suggest that, together, they may also represent a distinct evolutionary lineage that could warrant separate taxonomic status. Such a taxon should retain the name nauticus, either at the specific or subspecific level, given that is the oldest available name. Furthermore, we propose that SA has two species of Isoodon bandicoots, given the close genetic relationship of this lineage with I. fusciventer, and the presence of I. o. obesulus in the south-east of SA.

Within the 'western and southern group', multiple divergent mtDNA haplotype lineages were evident, some shared between the Mt Lofty Ranges and Franklin Islands populations, but others representing distinct lineages more closely related to haplotypes found in I. fusciventer, I. auratus and I. o. obesulus (south-east SA). These apparent genetic relationships most likely represent ancient connections, possibly by gene flow across the intervening landscape between these populations during suitable climatic periods, and the chance fixation of haplotypes by genetic drift in island populations. For example, St Francis Island has a fixed mtDNA haplotype that is most closely related to a haplotype from Mt Burr in the south-east of SA, but these haplotypes diverge by $\sim 1.7 \%$ (combined mtDNA data: Table 2), suggesting that it represents an ancient connection across the landscape between these populations and retention of an ancestral mtDNA lineage, and not recent gene flow across southern Australia. As reported by Li et al. (2014), individuals containing these divergent mtDNA haplotypes were part of the eastern ESU (Mount Burr subcluster) based on microsatellite markers, indicating that the divergent mtDNA haplotypes are not representative of an additional cryptic species present in the south-east of South Australia. Furthermore, the St Francis Island animals shared identical nuclear gene haplotypes with the Franklin Island, Kangaroo Island and Mt Lofty Ranges populations, distinct from those found in the south-east of SA, thus supporting its close genetic association with these former populations, rather than an association with the latter. The fixation of divergent mtDNA lineages within St Francis Island and the Franklin Islands populations, despite their close proximity $(\sim 30 \mathrm{~km})$, reflects their potential long-term isolation, or a lack of maternal gene flow among them, despite the likelihood of a land bridge between these islands being present during previous glacial maxima. Further investigation of nuclear gene data and morphology of these island populations is warranted to determine whether the mtDNA differences are associated with any additional genetic differences or whether they possibly result from male-biased dispersal.

\section{Taxonomic status of I. fusciventer and I. auratus}

Our genetic analyses support the distinction of I. fusciventer from I. o. obesulus, as recently proposed by Travouillon and Philips (2018), but uncertainties remain in the genetic distinction of I. fusciventer from I. auratus, and, as stated above, whether the range of I. fusciventer extends to SA (Mt Lofty Ranges, Kangaroo Island, Franklin and St Francis Islands). Mitochondrial DNA analyses provide evidence for polyphyly of the mtDNA haplotypes from different populations of both I. fusciventer and I. auratus, as well as populations from the Mt Lofty Ranges and other island populations in SA. It would be expected that each species would show reciprocal monophyly for mtDNA sequences if there was long-term isolation due to reproductive incompatibilities or geographic isolation (Avise 1994). However, coalescent theory also predicts that the progression from polyphyly to paraphyly to monophyly is strongly influenced by population size, with large populations taking much longer to achieve reciprocal monophyly than small populations (Kingman 2000). Therefore, given the possibility of historically high population sizes of Isoodon taxa (Short and Smith 1994) and relatively recent speciation (Westerman et al. 2012), it is likely that what are currently regarded as individual species/subspecies may not be reciprocally monophyletic with respect to other taxa (Kizirian and Donnelly 2004). Such a pattern of non-monophyly of mtDNA was observed for recently speciated rock-wallabies (Potter et al. 2015, 2017). However, signatures of isolation may still be evident from either paraphyly or the fixation of divergent haplotypes in different populations. In the case of I. fusciventer and I. auratus, although monophyly was not present, there were no shared mtDNA haplotypes and divergence among their mtDNA haplotypes was a minimum of $0.8 \%$ and, on average, $>1.6 \%$.

In contrast to the mtDNA phylogeographic analyses, the allozyme data provided some level of support for the genetic distinction of I. fusciventer and I. auratus, with each being discriminated from the other on both PCoA plots and NJ analyses, and also by fixed allozyme differences (Table S4, 
Supplementary Material). The analyses of nuclear gene sequence data also revealed the presence of distinct private haplotypes associated with I. fusciventer and I. auratus, supporting their genetic distinction. However, given that both species are currently allopatric, their genetic distinction based on the frequency of nuclear gene alleles is not entirely surprising. Future exon-capture genetic analyses, incorporating 1000s of nuclear gene loci (Bragg et al. 2017), and including museum specimens from the former range of I. auratus, which came close to the current and historical ranges of both I. obesulus and I. fusciventer, would be of considerable value for resolving whether there has been hybridisation among the taxa leading to introgression of mtDNA and other loci, an alternative explanation for the observed patterns. This approach is currently being employed through the Oz Mammals Genomics initiative, supported by Bioplatforms Australia (Eldridge et al. 2019).

\section{Recommendations for conservation management of Isoodon taxa}

Our results provide support for continued recognition of the subspecific status of Tasmanian I. o. affinis, and strongly suggest that the subspecies I. o. obesulus is restricted in its distribution to eastern mainland Australia, extending to the south-east of $\mathrm{SA}$. Taxonomic resolution of $I$. fusciventer and $I$. auratus is yet to be fully resolved and requires additional nuclear gene analyses in the future. The proposed delineation of $I$. o. obesulus suggests that the distribution, and hence the population size, of this taxon is significantly reduced compared with previous estimates and we recommend that the evaluation of conservation status under the EPBC Act be made on this basis, with the likely retention of the threat status of Endangered. Given the genetic distinctness of the animals from Mt Lofty Ranges, Kangaroo Island and Franklin and St Francis Islands localities of SA, the taxonomic status of these animals needs revision. However, until these data are available, we recommend managing these combined populations as a separate conservation unit.

On the basis of mtDNA data, the Tasmanian population of I. obesulus is genetically distinct from east coast mainland I. obesulus, supporting its current subspecies status as I. o. affinis, and represents the most closely related taxon to the endangered subspecies $I$. o. obesulus. For endangered taxa that have low genetic diversity, genetic rescue strategies can be employed through translocation of animals to increase genetic diversity within populations. Such a strategy is currently being planned for eastern barred bandicoots (Perameles gunnii). In this species, Tasmanian individuals are not genetically differentiated from those on the mainland and are being translocated to exclosures in Victoria, following the success of a similar genetic rescue program in mountain pygmy possums (Burramys parvus) in Victoria (Weeks et al. 2017; Aulsebrook 2018). In the case of I. o. obesulus, this study has confirmed that any implementation of a genetic rescue strategy should, in the first instance, focus on translocation within the delineated taxon, and not involve the differentiated Tasmanian I. o. affinis without further evaluation.

\section{Conclusions}

With expanded geographic sampling our analyses have provided a comprehensive assessment of phylogenetic patterns within southern brown and golden bandicoots of the genus Isoodon to support taxonomic assessment of the group. In doing so, we demonstrate the value of appropriate sampling and a multigenebased molecular analysis in resolving evolutionary relationships to provide a basis for taxonomic resolution. We also highlight the importance of an integrated approach to the conservation of closely related species, particularly in complexes where taxonomy may be unresolved, as a basis for effective management strategies.

\section{Conflicts of interest}

The authors declare no conflicts of interest.

\section{Acknowledgements}

We thank A. McLean, J. Packer, L. Price, K. Long, J. Bentley, N. Snelling, M. Bachmann, S. Jones, N. Haby, T. Horn, B. Haywood, R. Mengler, F. Christian, H. Nistelberger, A. Hillman, B. Chambers, D. Wrigley, P. Spencer, Department of Biodiversity, Conservation and Attractions (DBCA) Department of Biodiversity, Conservation and Attractions (DBCA) regional and Kimberley Islands Biological Survey staff, S. Troman, E. Dewar, M. Driessen (Department of Primary Industry, Parks, Water and Environment, Tasmania) for provision of samples and data. Additional samples were also sourced from the Australian National Wildlife Collection and Tasmanian Museum and Art Gallery. Funding for these sequence analyses was provided by Natural Resources Adelaide and Mount Lofty Ranges (AMLR) SA via the AMLR Threatened Fauna Ecologist, DBCA, the Australian Research Council Linkage grant (LP0668987), Native Vegetation Council, Wildlife Conservation Fund, DEWNR, the Department of Environment and Primary Industries (Victoria), The Roy and Marjory Edwards Scholarship provided by the Nature Foundation (SA) and through project 1.L.21 of the Invasive Animals Cooperative Research Centre (PI Stephen Sarre). We thank Chris Burridge and an anonymous reviewer for comments on a previous version of the manuscript and Kenny Travouillon for taxonomic advice. Sample collections in this study were performed under the University of Adelaide Animal Ethics Committee (project no. S-2011-041), Department of the Environment and Heritage (DEH) permit to undertake scientific research (permit no. G23771-13), Department of Biodiversity, Conservation and Attractions licence to use animals for scientific purposes (permit no. U10/2018) and under a Department of Primary Industries, Parks, Water and Environment (Tasmania) permit TFA 12289.

\section{References}

Adams, M., Page, T. J., Hurwood, D. A., and Hughes, J. M. (2013). A molecular assessment of species boundaries and phylogenetic affinities in Mogurnda (Eleotridae): a case study of cryptic biodiversity in the Australian freshwater fishes. Marine and Freshwater Research 64, 920-993. doi:10.1071/MF12237

Adams, M., Raadik, T. A., Burridge, C., and Georges, A. (2014). Global biodiversity assessment and hyper-cryptic species complexes: more than one species of elephant in the room? Systematic Biology 63, 518-533. doi:10.1093/sysbio/syu017

Amrine-Madsen, H., Scally, M., Westerman, M., Stanhope, M. J., Krajewski, C., and Springer, M. S. (2003). Nuclear gene sequences provide evidence for the monophyly of australidelphian marsupials. Molecular Phylogenetics and Evolution 28, 186-196. doi:10.1016/S1055-7903(03) 00122-2

Aulsebrook, A. (2018). Back from the brink: crowdfunding for the genetic rescue of eastern barred bandicoots. Remember the Wild. Available at: http://www.rememberthewild.org.au/

Avise, J. C. (1994). 'Molecular Markers, Natural History and Evolution.' (Chapman and Hall: New York.) 
Avise, J. C., and Bull, R. M. J. (1990). Principles of genealogical concordance in species concepts and biological taxonomy. Oxford Surveys in Evolutionary Biology 7, 45-67.

Bragg, J. G., Potter, S., Bi, K., Catullo, R., Donnellan, S. C., Eldridge, M. D. B., Joseph, L., Keogh, S., Oliver, P., Rowe, K. C., and Moritz, C. (2017). Resources for phylogenomic analyses of Australian terrestrial vertebrates. Molecular Ecology Resources 17, 869-876.

Burbidge, A. A., and McKenzie, N. L. (1989). Patterns in the modern decline of Western Australia's vertebrate fauna: causes and conservation implications. Biological Conservation 50, 143-198. doi:10.1016/ 0006-3207(89)90009-8

Burgin, C. J., Colella, J. P., Kahn, P. L., and Upham, N. S. (2018). How many species of mammals are there? Journal of Mammalogy 99, 1-14. doi:10.1093/jmammal/gyx147

Campbell, C. D., Sarre, S. D., Stojanovic, D., Gruber, B., Medlock, K., Harris, S., MacDonald, A. J., and Holleley, C. E. (2018). When is a native species invasive? Incursion of a novel predatory marsupial detected using molecular and historical data. Diversity \& Distributions 24, 831-840. doi:10.1111/ddi.12717

Close, R. L., Murray, J. D., and Briscoe, D. A. (1990). Electrophoretic and chromosome surveys of the taxa of short-nosed bandicoots within the genus Isoodon. In 'Bandicoots and Bilbies'. (Eds J. H. Seebeck, P. R. Brown, R. L. Wallis, and C. M. Kemper.) pp. 19-27. (Surrey Beatty: Sydney.)

Coates, T, Nicholls, D, and Willig, R (2008). The distribution of the Southern Brown Bandicoot Isoodon Obesulus in south central Victoria. The Victorian Naturalist 125, 128-139.

Department of Environment and Conservation (NSW) (2006). Southern Brown Bandicoot (Isoodon obesulus) recovery plan, Hurstville, NSW. Available at: https://www.environment.nsw.gov.au/-/media/ $\mathrm{OEH} /$ Corporate-Site/Documents/Animals-and-plants/Recovery-plans/ southern-brown-bandicoot-isoodon-obesulus-recovery-plan.pdf

Driessen, M. M., and Rose, R. K. (2015). Isoodon obesulus (Peramelemorphia: Peramelidae). Mammalian Species 47, 112-123. doi:10.1093/mspecies/ sev012

Eldridge, M. D. B., Deakin, J. E., MacDonald, A. J., Byrne, M., Fitzgerald, A., Johnson, R. N., Moritz, C., Palmer, S., and Young, A. (2019). The Oz Mammals Genomics (OMG) initiative: developing genomic resources for mammal conservation at a continental scale. Australian Zoologist, in press.

Ely, C. V., Bordignon, S. A. de L., Trevisanc, R., and Boldrini, I. I. (2017). Implications of poor taxonomy in conservation. Journal for Nature Conservation 36, 10-13. doi:10.1016/j.jnc.2017.01.003

Excoffier, L., and Lischer, H. E. L. (2010). Arlequin suite ver 3.5: a new series of programs to perform population genetics analyses under Linux and Windows. Molecular Ecology Resources 10, 564-567. doi:10.1111/ j.1755-0998.2010.02847.x

Frankham, R., Ballou, J. D., Eldridge, M. D. B., Lacy, R. C., Ralls, K., Dudash, M. R., and Fenster, C. B. (2011). Predicting the probability of outbreeding depression. Conservation Biology 25, 465-475. doi:10.1111/j.1523-1739.2011.01662.x

Frankham, G. J., Handasyde, K. A., and Eldridge, M. D. B. (2016). Evolutionary and contemporary responses to habitat fragmentation detected in a mesic zone marsupial, the long-nosed potoroo (Potorous tridactylus) in south-eastern Australia. Journal of Biogeography 43, 653-665. doi:10.1111/jbi.12659

Fu, Y.-X. (1997). Statistical tests of neutrality of mutations against population growth, hitchhiking and background selection. Genetics 147 , 915-925.

Fumagalli, L., Pope, L. C., Taberlet, P., and Moritz, C. (1997). Versatile primers for the amplification of the mitochondrial DNA control region in marsupials. Molecular Ecology 6, 1199-1201. doi:10.1046/j.1365-294X.1997.00298.x

Groves, C. P. (2005). Order Peramelemorphia. In 'Mammal Species of the World: A Taxonomic and Geographic Reference'. 3rd edn. (Eds D. E. Wilson, and D. M. Reeder.) pp. 38-42. (Johns Hopkins University Press: Baltimore.)

Gutiérrez, E. E., and Helgen, K. M. (2013). Outdated taxonomy blocks conservation. Nature 495, 314doi:10.1038/495314e
Hasegawa, M., Kishino, H., and Yano, T. (1985). Dating of the human-ape splitting by a molecular clock of mitochondrial DNA. Journal of Molecular Evolution 22, 160-174. doi:10.1007/BF02101694

Hey, J. (2010). Isolation with migration models for more than two populations. Molecular Biology and Evolution 27, 905-920. doi: 10.1093/molbev/msp296

Ho, S. Y. W., Lanfear, R., Bromham, L., Phillips, M. J., Soubrier, J., Rodrigo, A. G., and Cooper, A. (2011). Time-dependent rates of molecular evolution. Molecular Ecology 20, 3087-3101. doi:10.1111/j.1365294X.2011.05178.x

Jackson, S. M., and Groves, C. P. (2015). 'Taxonomy of Australian Mammals.' (CSIRO Publishing: Melbourne.)

Kingman, J. F. C. (2000). Origins of the coalescent 1974-1982. Genetics 156, 1461-1463.

Kizirian, D., and Donnelly, M. A. (2004). The criterion of reciprocal monophyly and classification of nested diversity at the species level. Molecular Phylogenetics and Evolution 32, 1072-1076. doi:10.1016/j. ympev.2004.05.001

Laerm, J., Avise, J. C., Patton, J. C., and Lansman, R. A. (1982). Genetic determination of the status of an endangered species of pocket gopher in Georgia. The Journal of Wildlife Management 46, 513-518. doi:10.2307/ 3808669

Legge, S., Woinarski, J. C. Z., Burbidge, A. A., Palmer, R., Ringma, J., Radford, J. Q., Mitchell, N., Bode, M., Wintle, B., Baseler, M., Bentley, J., Copley, P., Dexter, N., Dickman, C. R., Gillespie, G. R., Hill, B., Johnson, C. N., Latch, P., Letnic, M., Manning, A., McCreless, E. E., Menkhorst, P., Morris, K., Moseby, K., Page, M., Pannell, D., and Tuft, K. (2018). Havens for threatened Australian mammals: the contributions of fenced areas and offshore islands to the protection of mammal species susceptible to introduced predators. Wildlife Research 45, 627-644. doi:10.1071/WR17172

Li, Y., Lancaster, M. L., Carthew, S. M., Packer, J. G., and Cooper, S. J. B. (2014). Delineation of conservation units in an endangered marsupial, the southern brown bandicoot (Isoodon obesulus obesulus) in South Australia/western Victoria, Australia. Australian Journal of Zoology 62, 345-359. doi:10.1071/ZO14038

Li, Y., Lancaster, M. L., Cooper, S. J. B., Taylor, A. C., and Carthew, S. M. (2015). Population structure and gene flow in the endangered southern brown bandicoot (Isoodon obesulus obesulus) across a fragmented landscape. Conservation Genetics 16, 331-345. doi:10.1007/s10592014-0661-5

Li, Y., Cooper, S. J. B., Lancaster, M. L., Packer, J. G., and Carthew, S. M. (2016). Comparative population genetic structure of the endangered southern brown bandicoot, Isoodon obesulus, in fragmented landscapes of southern Australia. PLoS One 11, e0152850doi:10.1371/journal. pone. 0152850

Lyne, A. G., and Mort, P. A. (1981). Comparison of skull morphology in the marsupial bandicoot genus Isoodon: its taxonomic implications and notes on a new species, Isoodon arnhemensis. Australian Mammalogy 4, 107-133.

MacDonald, A. J., and Sarre, S. D. (2017). A framework for developing and validating taxon-specific primers for specimen identification from environmental DNA. Molecular Ecology Resources 17, 708-720. doi:10.1111/1755-0998.12618

MacDonald, A. J., Sarre, S. D., FitzSimmons, N. N., and Aitken, N. (2011). Determining microsatellite genotyping reliability and mutation detection ability: an approach using small-pool PCR from sperm DNA. Molecular Genetics and Genomics 285, 1-18. doi:10.1007/s00438-010-0577-9

Mace, G. M. (2004). The role of taxonomy in species conservation. Philosophical Transactions of the Royal Society of London. Series B, Biological Sciences 359, 711-719. doi:10.1098/rstb.2003.1454

McKenzie, N. L., Burbidge, A. A., Baynes, A., Brereton, R. N., Dickman, C. R., Gordon, G., Gibson, L. A., Menkhorst, P. W., Robinson, A. C., Williams, M. R., and Woinarski, J. C. Z. (2007). Analysis of factors implicated in the recent decline of Australia's mammal fauna. Journal of Biogeography 34, 597-611. doi:10.1111/j.1365-2699. 2006.01639.x 
Menkhorst, P., and Knight, F. (2011) 'A Field Guide to the Mammals of Australia.' (Oxford University Press: Melbourne.)

Meredith, R. W., Westerman, M., and Springer, M. S. (2008). A timescale and phylogeny for "bandicoots" (Peramelemorphia: Marsupialia) based on sequences for five nuclear genes. Molecular Phylogenetics and Evolution 47, 1-20. doi:10.1016/j.ympev.2008.01.002

Moritz, C (1994). Defining 'Evolutionarily Significant Units' for conservation. Trends in Ecology and Evolution 9, 373-375. doi:10.1016/ 0169-5347(94)90057-4

Morris, K., Page, M., Kay, R., Renwick, J., Desmond, A., Comer, S., Burbidge, A., Kuchling, G., and Sims, C. (2015). Forty years of fauna translocations in Western Australia: lessons learned. In 'Advances in Reintroduction Biology of Australian and New Zealand Fauna'. (Eds D. P. Armstrong, M. W. Hayward, D. Moro, and P. J. Seddon.) pp. 217-235. (CSIRO Publishing: Melbourne.)

Moseby, K. E., Hill, B. M., and Read, J. L. (2009). Arid recovery - a comparison of reptile and small mammal populations inside and outside a large rabbit, cat, and fox-proof exclosure in arid South Australia. Austral Ecology 34, 156-169. doi:10.1111/j.1442-9993.2008.01916.x

Osborne, M. J., and Christidis, L. (2001). Molecular phylogenetics of Australo-Papuan possums and gliders (family Petauridae). Molecular Phylogenetics and Evolution 20,211-224. doi:10.1006/mpev.2001.0960

Ottewell, K., Dunlop, J., Thomas, N., Morris, K., Coates, D., and Byrne, M. (2014). Evaluating success of translocations in maintaining genetic diversity in a threatened mammal. Biological Conservation 171, 209-219. doi:10.1016/j.biocon.2014.01.012

Paull, D. J. (1993). The distribution, ecology and conservation status of the Southern Brown Bandicoot (Isoodon obesulus obesulus) in South Australia. MA Thesis, University of Adelaide.

Paull, D. J. (1995). The distribution of the southern brown bandicoot (Isoodon obesulus obesulus) in South Australia. Wildlife Research 22, 585-600. doi:10.1071/WR9950585

Paull, D. J., Mills, D. J., and Claridge, A. W. (2013). Fragmentation of the southern brown bandicoot Isoodon obesulus: unraveling past climate change from vegetation clearing. International Journal of Ecology 2013, 536524doi:10.1155/2013/536524

Pedler, R. D., West, R. S., Read, J. L., Moseby, K. E., Letnic, M., Keith, D. A., Leggett, K. D., Ryall, S. R., and Kingsford, R. T. (2018). Conservation challenges and benefits of multispecies reintroductions to a national park - a case study from New South Wales, Australia. Pacific Conservation Biology 24, 397-408. doi:10.1071/PC17058

Pope, L. C., Storch, D., Adams, M., Moritz, C., and Gordon, G. (2001). A phylogeny for the genus Isoodon and a range extension for Isoodon obesulus peninsulae based on mtDNA control region and morphology. Australian Journal of Zoology 49, 411-434. doi:10.1071/ ZO00060

Potter, S., Moritz, C., and Eldridge, M. D. B. (2015). Gene flow despite complex Robertsonian fusions among rock-wallaby (Petrogale) species. Biology Letters 11, 20150731doi:10.1098/rsbl.2015.0731

Potter, S., Bragg, J. G., Blom, M. P. K., Deakin, J. E., Kirkpatrick, M., Eldridge, M. D. B., and Moritz, C. (2017). Chromosomal speciation in the genomics era: disentangling phylogenetic evolution of rock-wallabies. Frontiers in Genetics 8, 10doi:10.3389/fgene.2017.00010

Radford, J. Q., Woinarski, J. C. Z., Legge, S., Baseler, M. E., Bentley, J., Burbidge, A. A., Bode, M., Copley, P., Dexter, N., Dickman, C. R., Gillespie, G., Hill, B., Johnson, C. N., Kanowski, J., Latch, P., Letnic, M., Manning, A., Menkhorst, P., Mitchell, N., Morris, K., Moseby, K., Page, M., and Ringma, J. (2018). Degrees of population-level susceptibility of Australian terrestrial non-volant mammal species to predation by the introduced red fox (Vulpes vulpes) and feral cat (Felis catus). Wildlife Research 45, 645-657. doi:10.1071/WR18008
Richardson, B. J., Baverstock, P. R., and Adams, M. (1986). 'Allozyme Electrophoresis: a Handbook for Animal Systematics and Population Studies.' (Academic Press: Sydney.)

Robinson, N. M., MacGregor, C. I., Hradsky, B. A., Dexter, N., and Lindenmayer, D. B. (2018). Bandicoots return to Booderee: initial survival, dispersal, home range and habitat preferences of reintroduced southern brown bandicoots (eastern subspecies; Isoodon obesulus obesulus). Wildlife Research 45, 132-142. doi:10.1071/ WR17040

Rodríguez, F., Oliver, J. F., Marín, A., and Medina, J. R. (1990). The general stochastic model of nucleotide substitutions. Journal of Theoretical Biology 142, 485-501. doi:10.1016/S0022-5193(05)80104-3

Short, J., and Smith, A. P. (1994). Mammal decline and recovery in Australia. Journal of Mammalogy 75, 288-297. doi:10.2307/1382547

Southgate, R, Palmer, C, Adams, M, Masters, P, Triggs, P, and Woinarski, J (1996). Population and habitat characteristics of the golden bandicoot (Isoodon auratus) on Marchinbar Island, Northern Territory. Wildlife Research 23, 647-664. doi:10.1071/WR9960647

Stamatakis, A., Hoover, P., and Rougemont, J. (2008). A rapid bootstrap algorithm for the RAxML web-servers. Systematic Biology 57, 758-771. doi:10.1080/10635150802429642

Stephens, M., and Scheet, P. (2005). Accounting for decay of linkage disequilibrium in haplotype inference and missing-data imputation. American Journal of Human Genetics 76, 449-462. doi:10.1086/ 428594

Stephens, M., Smith, N., and Donnelly, P. (2001). A new statistical method for haplotype reconstruction from population data. American Journal of Human Genetics 68, 978-989. doi:10.1086/319501

Tajima, F. (1989). Statistical method for testing the neutral mutation hypothesis by DNA polymorphism. Genetics 123, 585-595.

Tamura, K., Stecher, G., Peterson, D., Filipski, A., and Kumar, S. (2013). MEGA6: Molecular Evolutionary Genetics Analysis version 6.0. Molecular Biology and Evolution 30, 2725-2729. doi:10.1093/molbev/ mst197

Travouillon, K., and Philips, M. J. (2018). Total evidence analysis of the phylogenetic relationships of bandicoots and bilbies (Marsupialia: Peramelemorphia): reassessment of two species and description of a new species. Zootaxa 4378, 224-256. doi:10.11646/zootaxa.4378.2.3

Warburton, N. M., and Travouillon, K. J. (2016). The biology and palaeontology of the Peramelemorphia: a review of current knowledge and future research directions. Australian Journal of Zoology 64, 151-181. doi:10.1071/ZO16003

Weeks, A. R., Sgro, C. M., Young, A. G., Frankham, R., Mitchell, N. J., Miller, K. A., Byrne, M., Coates, D. J., Eldridge, M. D., Sunnucks, P., and Breed, M. F. (2011). Assessing the benefits and risks of translocations in changing environments: a genetic perspective. Evolutionary Applications 4, 709-725. doi:10.1111/j.1752-4571.2011.00192.x

Weeks, A. R., Heinze, D., Perrin, L., Stoklosa, J., Hoffmann, A. A., van Rooyen, A., Kelly, T., and Mansergh, I. (2017). Genetic rescue increases fitness and aids rapid recovery of an endangered marsupial population. Nature Communications 8, 1071doi:10.1038/s41467-01701182-3

Westerman, M, and Krajewski, C (2000). Molecular relationships of the Australian bandicoot genera Isoodon and Perameles (Marsupialia: Peramelina). Australian Mammalogy 22, 1-8. doi:10.1071/ AM00001

Westerman, M, Kear, B. P., Aplin, K, Meredith, R. W., Emerling, C, and Springer, M. S. (2012). Phylogenetic relationships of living and recently extinct bandicoots based on nuclear and mitochondrial DNA sequences. Molecular Phylogenetics and Evolution 62, 97-108. doi:10.1016/j. ympev.2011.09.009 
Woinarski, J. C. Z., Burbidge, A. A., and Harrison, P. L. (2014). 'The Action Plan for Australian Mammals 2012.' (CSIRO Publishing: Melbourne.)

Woinarski, J. C. Z., Burbidge, A. A., and Harrison, P. L. (2015). Ongoing unraveling of a continental fauna: decline and extinction of Australian mammals since European settlement. Proceedings of the National Academy of Sciences of the United States of America 112, 4531-4540. doi:10.1073/pnas. 1417301112

Yang, Z. (1996). Among-site rate variation and its impact on phylogenetic analyses. Trends in Ecology \& Evolution 11, 367-372. doi:10.1016/ 0169-5347(96)10041-0
Zachos, F. E., Apollonio, M., Bärmann, E. V., Festa-Bianchet, M., Göhlich, U., Habel, J. C., Haringa, E., Kruckenhauser, L., Lovari, S., McDevitt, A. D., Pertoldi, C., Rössner, G. E., Sánchez-Villagra, M. R., Scandura, M., and Suchentrunk, F. (2013). Species inflation and taxonomic artefacts - a critical comment on recent trends in mammalian classification. Mammalian Biology 78, 1-6. doi:10.1016/j.mambio.2012.07.083

Zenger, K. R., Eldridge, M. D. B., and Johnston, P. G. (2005). Phylogenetics, population structure and genetic diversity of the endangered southern brown bandicoot (Isoodon obesulus) in south-eastern Australia. Conservation Genetics 6, 193-204. doi:10.1007/s10592-004-7828-4

Handling Editor: Janine Deakin 